\title{
A European lens upon adult and lifelong learning in Asia
}

\author{
Michael Osborne $^{1} \cdot$ Katarzyna Borkowska $^{1}$
}

Published online: 13 May 2017

(C) The Author(s) 2017. This article is an open access publication

\begin{abstract}
In this article, we seek to assess the extent to which adult and lifelong learning policies and practices in Asia have distinctiveness by comparison to those found in western societies, through an analysis of inter-governmental, national and regional policies in the field. We also inform our study through the analysis of the work of organisations with an international remit with a specific focus on Asia and Europe. In one case, the Asia-Europe Meeting Lifelong Learning (ASEM LLL) Hub has a specific function of bringing together researchers in Asia and Europe. In another, the PASCAL Observatory has had a particular focus on one aspect of lifelong learning, that of learning cities, with a concentration in its work on Asia and Europe. We focus on learning city development as a particular case of distinction in the field. We seek to identify the extent to which developments in the field in Asia have influenced and have been influenced by practices elsewhere in world, especially in Europe, and undertake our analysis using theories of societal learning/the learning society, learning communities and life-deep learning. We complement our analysis through assessment of material contained in three dominant journals in the field, the International Journal of Lifelong Education, the International Review of Education and Adult Education Quarterly, each edited in the west.
\end{abstract}

Michael Osborne

Michael.Osborne@glasgow.ac.uk

Katarzyna Borkowska

Katarzyna.Borkowska@glasgow.ac.uk

University of Glasgow, Glasgow, UK
Keywords Societal learning · Learning society $\cdot$ Learning communities · Lifelong learning $\cdot$ Lifewide learning $\cdot$ Lifedeep learning

\section{Introduction}

There are many longstanding debates concerning the role and purpose of adult and lifelong learning with the common discourse being that concerned with the challenges posed by socio-economic and demographic changes. In Europe, the European Commission (2010) has argued that increasing globalisation, rapid technological change, an ageing population and the demands of a more knowledgeand skills-intensive European labour market have resulted in the need to provide adults with opportunities to increase their skill levels in order to meet these challenges. The European Union considers education (including lifelong learning) and the attainment of qualifications as a major element to ensure competitiveness in the globalised knowledge economy. Hence, in recent decades, education and training, and lifelong learning policies have become integrated features in the arsenals of the vast majority of the $28 \mathrm{EU}$ member states. However, reflecting the narrow and dominant economic perspective, these policies generally focus on means to enhance access to the labour market, and it is considered primarily to be an individual responsibility to up-date skills, competences and aptitudes with the state as a facilitator. There is, however, considerable debate as to whether or not these policies have achieved their proclaimed objectives. Allmendinger and Leibfried (2003), Allemendinger and Nikolai (2010), Heisig and Solga (2014), Hanushek et al. (2011) amongst others have concluded that such policies will not alone achieve the other key concern within Europe of achieving social equity 
and inclusion. This they argue will only come about through combination with other social and labour marketoriented policies.

In Europe, inequity in terms of access to programmes of adult education takes many forms. For example, the participation rates in adult education of highly educated people, those in good employment positions and those between 35 and 45 years are considerably higher than those from a range of socially vulnerable groups (EC 2013). In short, European education strategies still face challenges to integrate those exposed to risks of social exclusion in education systems.

Perhaps, the most vulnerable groups in Europe have been young people (16-25) and people older than 45 years, both groups having been poorly served by adult education markets during a time of high unemployment caused by the international financial crisis. Of course, each of these groups is not homogenous and each contains sub-groups that include the disabled, ethnic minority groups including Roma, people with care responsibilities, older adults in the third age beyond retirement and those in remote geographical locations with increased vulnerability. These subgroups are exposed to additional and multiple risks of unemployment and/or social exclusion and rarely do adult education markets give particular attention to their needs. Furthermore, publicly funded programmes seem only to have minor impacts on their labour market position often due to a poor linkage between economic, employment and social policies, and to key stakeholders who might assure such a close linkage. Gender importantly continues to be a major factor of discrimination in relation to labour market opportunities.

The first generational group, youth, faces the enormous problem of entering the labour market and starting a professional career. Data from across Europe show that youth unemployment is one of the major social problems of the EU and is given special attention by the new Europe 2020 strategy. In some countries such as Spain, Portugal, Greece or Italy, the youth unemployment rate has risen to over $50 \%$. In general, "low-skilled young men have been the most affected in terms of declining employment and labour force participation, while low-skilled prime-age men have been the hardest hit in terms of rising unemployment" (OECD 2013, p. 21). The second group, those over 45 years in age, has been excluded from lifelong learning opportunities in the majority of EU countries (Houston et al. 2016), and they also face considerable labour market risks. Reforms in pension systems in most EU member states have meant that this cohort is staying longer in the labour market with the effect that now their (un)-employment rates are comparable to the age group between 30 and 45 years. And, once unemployed, older workers face severe difficulties in finding new jobs (see Heywood and
Jirjahn 2015). This results in higher long-term unemployment for older workers in Europe, and under-employment (seeking further hours of work and available to do so). Over $20 \%$ of part-time workers in Europe are under-employed, this rate rising to $72 \%$ in Greece, and of underemployed workers, over two-thirds in Europe as a whole are women, irrespective of their education level (Eurostat 2015). Many in those countries most affected by the economic crisis have given up looking for work.

Furthermore, those not in work and not seeking work, because they are in retirement, have faced declines in the availability of publicly funded non-vocational lifelong learning opportunities. This form of adult education, which has taken a variety of forms, can broadly be described as having an orientation towards shaping active citizenship, and encouraging health and well-being. It has been most prominent in the Nordic countries (for example, municipal adult education (MAE) folk high schools (FHSs) of Sweden) and in the UK (for example, university liberal adult education (LAE)). In the case of MAE and FHSs in Sweden, Fejes (2010) and Sandberg et al. (2016), both point to the increasing emphasis on the labour market function of provision, and in the case of university LAE in the UK, it is now in terminal decline (see Osborne 2003) with increasingly the only provision available being self-organised or through the private sector. These trends ignore the logic of the wider benefits of learning through the life course not only for the individual, but also for the state, especially in terms of reduced costs of health care (Osborne 2014). Further, the emphasis on human capital development disregards broader conceptions of the societal learning Yorks and Barto (2015) and the learning society, popularized from UNESCO by Faure et al. (1972) and conceptually developed, amongst others, by Husén (1974, 1986), (Raggett et al. 1995), Ranson (1998), Jarvis (2007). Societal learning refers to learning within systems that extend beyond particular organisations and the importance of networks that cross sectors. The concept of the learning society implies the embedding of learning within all aspects of life's activities with life and learning being complementary. In this sense, learning becomes life-deep, a concept we return to later in this article.

To an extent, we can see from the policy literature some parallels to the dominant European paradigm of lifelong learning as a response to the economy in Asia. In Malaysia (Ministry of Education 2011: xv), for example, 'lifelong learning is the third pillar of human capital development'. The focus on skills in Malaysia encompassed a range of elements that would be familiar in Europe, including workplace learning, access to formal learning, accreditation of prior learning and learning within small to medium sized enterprises (SMEs). Basic skills, including the development of functional literacy, are also an issue of 
significance, but not to the extent of some other parts of Asia. In Thailand, for example, Sungsri (2009) argues that the National Education Plan of 1987 and the National Education Act in 1999 has provided the conditions for lifelong learning that is far-reaching in the sense of the sectors involved, types of activities, and orientation with not simply a focus on vocational skills, but also to literacy and non-formal education provision equivalent to that provided by primary and secondary schools. Of particular importance are basic skills for those in rural areas, especially farmers. This of course reflects that stark statistic of a recent report concerning the implementation of Education for All in the Asia-Pacific region that:

' $35 \%$ of Thailand's population aged 25 years and older did not complete primary education, $22 \%$ completed primary [International Standard Classification of Education (ISCED) 1], 11\% finished lower secondary (ISCED 2) and 14\% finished upper secondary (ISCED 3)'. (UNESCO 2015a, p. 30).

A similar situation exists in a number of other Asian countries, where large cohorts of adults over 25 have received no formal schooling at all. In India, with the development of a National Skills Development Initiative, we can observe a rhetoric that is very similar to that of the EU and its constituent countries. The policy of the Indian government, in its 11 th 5 -year plan refers to the 'importance of education, in its broadest sense of development of youth' ... as ... 'the most crucial input for empowering people with skills and knowledge and giving them access to productive employment in the future (Government of India Planning Commission 2006, p. 4). This is placed in the context of huge challenges for equitable access to learning for many groups including women, those in rural settings, the disabled and those in rural areas.

India is but one country in Asia where challenges are multiple. Poverty, environmental disasters because of climate change, and forced and voluntary migration require particular responses from adult and lifelong learning. At a recent ASEM LLL Hub conference ${ }^{1}$ hosted by South East Asia Ministers of Education Organisation Regional Centre for Lifelong Learning (SEAMEO CELL) in Ho Chi Ming City, a number of contributions considered topics that included the role of adult literacy in disaster risk reduction policies and the role of community learning centres in building and enhancing resilience. Migration, an issue that is at the top of the policy agenda in Europe following the conflict in Syria and other parts of the middle east, and which is a substantial underpinning of dissatisfaction expressed towards national governments and the EU, is of course an international issue. In Thailand, for example,

$\overline{{ }^{1} \text { See http://asemlllhub.org/events/vietnam2016/programme/. }}$ there are large numbers of migrant labourers from Myanmar, Laos and Cambodia in Bangkok, and at another recent ASEM conference, Boriboon (2016) considered these issues in the context of education for citizenship.

However, as GDP rises, then focus can and does changes. So for example in Japan, the Basic Act on Education, includes a lifelong learning perspective, and provision at both national and local level for social education, which includes creating a range of opportunities to learn and establishing libraries, museums, community centres and other social education facilities with a learning function (Government of Japan 2008). The Ministry of Education, Culture, Sports, Science and Technology (MEXT 2008) also promotes national lifelong learning festivals. What is notable about Japan and some other countries in Asia, from an external perspective, is the concern for lifelong learning in legislation. Korea perhaps goes further than Japan with a specific Lifelong Education Act (Ministry of Education, Science and Technology 2009), and a National Lifelong Learning Promotion Plan, now in its third edition for the period 2013-2017. Quite striking, from that third plan, is the statement that:

'Lifelong learning is acknowledged as a requisite for individual happiness and prosperity in an aging society. Along with national competitiveness, the factors such as social trust, quality jobs, freedom of individual choice, and political participation can determine national welfare'. (NILE 2013, p. 1).

The specific orientation on the development of communities and on learning cities is also significant and a focus of the next section of this article.

\section{Learning cities and the PASCAL observatory}

One particular unifying field between Europe and Asia, within which there is a widely held perception of an Asian dominance in the last decade (see Kearns 2015) is that of the development of learning cities, a field that the PASCAL Observatory has taken a frontier role within, paralleling the work of the UNESCO Institute for Lifelong Learning (UIL) and its Global Learning Cities Network (GLCN). Whilst the concept of the learning city in the late 20th century emerged from debates with UNESCO (Faure et al. 1972; Delors et al. 1996) and (OECD 1992, 2000) and initially stimulated most activity in Europe (Commission of the European Union (CEC) 2000, 2001, 2003) and to a lesser extent North America, it seems clear that currently it has taken a much stronger hold in policy and practice in Asia. In an editorial for a special issue of the International Review of Education on learning cities, Osborne et al. (2013) point to the emergence of East Asia as a locus. 
The underlying concept within learning city initiatives, including those of UNESCO in the last decade, has been the development of a learning society in which a range of agencies beyond formal providers become vectors for learning, and that learning opportunities not only are lifelong, but also life-wide in as much as it is spatially pervasive (Maclachlan and Osborne 2009). Whilst the lifewide learning dimension, although less used than lifelong dimension, is used in debate, it is perhaps the even more rarely used notion of a life-deep learning that might be a starting point for drawing distinctions between Asian and European perspectives.

Wallin et al. (2005) speak of depth of engagement, and complex learning that is difficult to implement. Banks et al. have argued that life-deep learning concerns:

"Beliefs, values, ideologies, and orientations to life. Life-deep learning scaffolds all our ways of approaching challenges and undergoing change. Religious, moral, ethical, and social learning bring lifedeep learning that enables us to guide our actions, judge ourselves and others, and express to ourselves and others how we feel and what we believe". (2007, p. 15)

Longworth (2003, p. 46) argues that life-deep learning 'is essential for international harmony', and is concerned with an 'awareness and understanding of particular issues in the wider world beyond our immediate environment'. Longworth's laudable goal of international harmony through a deep learning engagement is far from achieved, but it is interesting to note that it is found as a principle at a national level in some of the learning cities in Asia. For example in his opening address to the first UNESCO Global Learning Cities conference in Beijing in 2013, China's Vice-President, Liu Yandong, in advocating exchanges of experiences between learning cities, spoke of his wish to:

“... encourage more countries and cities to participate in a policy dialogue, a sharing of ideas, action research and capacity building, sharing our experiences and sophisticated, high-quality resources to build a better and more harmonious global village." (UNESCO Institute for Lifelong Learning 2014, p. 50)

Concepts such as 'harmony' clearly derive from Confucian influences, and as (Yang et al. 2015, p. 2) argue, extend across families, community and society overall with groups, including cities, themselves being sub-ordinate to the individual. These authors argue that this distinguishes some of the countries of East Asia from the western world, although it has also been argued that the quest for a harmonious society has much in common with equally elusive western goal of the learning society (Sun 2007). The stronger impetus for the development of learning cities in Asia, however, may provide some evidence for this assertion, although neither East Asia nor Europe is homogeneous in terms of the relative stress on communitarianism and individualism. Furthermore, the dominance of the knowledgeable sage or teacher in Confucianism impedes innovation, entrepreneurship, flexibility, meta-cognition and self-directedness in learning, features of lifelong learners lauded in the West (see Mwaikokesya et al. 2014). It also facilitates conformity, which of course allows top-down central planning. To an extent, some of the models in East Asia, however, have managed to combine some of the best aspects of traditional values of community with some of the features of individualism. For example, Byun et al. (2005) speak of a learning city type in Korea, which reinforces the self-autonomous learning community that operates programmes that are response to the needs of citizens.

As during the 1980s the use of the 'learning city' developed, so did the associated idea of 'learning communities', and indeed Faris (2005) absorbs the two ideas within one framework, scale being the differentiating feature. He speaks of learning communities as

"neighbourhoods, villages, towns, cities and regions in which the concept of lifelong learning is explicitly used as an organizing principle and social goal as the learning resources of every one of the five sectors of the community-civic, economic (private-cooperative enterprise), public (e.g. libraries, museums, health and social agencies), education, and voluntary-are mobilized to foster environmentally sustainable economic development and social inclusion". (Faris 2010, p. 4)

Advocates of learning cities have argued that learning comes about in and is supported by cultural and social interactions that occur in communities within which 'members share common goals, take efforts to attain them and so seek a common understanding and create shared knowledge' (Eckert et al. 2012). This focus on the development of community, whilst part of the rhetoric of learning cities in all parts of the world, is perhaps also one of the strengths of the focus in Asian developments, and has a reality beyond the rhetoric. The development of the learning city is not simply about improving economic competitiveness and attracting inward investment (Larsen 1999) or about creating a more inclusive society though providing great educational opportunity and equity. It is something deeper that pervades all aspects of life, and is a manifestation of a deep commitment to learning as the basis for the development of a society based on sound ethical and moral principles, and with a common and shared set of goals.

Han and Makino (2013) when analysing learning cities in Japan, China and the Republic of Korea have argued that the upsurge of the development in these countries has been 
because it has been based on a community relations model in a period of dramatic socio-economic change. They suggest that Asian developments have within their foundations a collective ethos that contrasts with the individualism and competency-based approaches found in Europe. Yang (2012) had already argued that the promotion of lifelong learning and the development of learning societies would not occur purely through a top-down approach from government, but also through efforts at smaller levels of geography: regions, cities and communities. Asian developments do seem to encompass both top-down and bottomup approaches, linked to a common collective ethos. The willingness and ability of many Asian societies to legislate for lifelong learning and to inspire collective community action appear to the outside observer to contrast with much of the rest of the world. Yang illustrates the top-down approach when citing China's National Plan Outline for Medium and Long-term Education Reform and Development (2010-2020) and the National Scheme on Building a Learning Society in Vietnam (2011-2020). China's plan specified building a learning society by 2020 in which there is universal opportunity that is lifelong and life-wide (Ministry of Education of China 2010). The Vietnamese scheme proposed a scheme to pilot the building of learning provinces, learning cities, learning districts and learning communities. Earlier, we made reference to legislation for lifelong learning in the Republic of Korea.

An emphasis on the role of community in Asian societies is born out in a recent report commissioned by NILE/ UIL (2017) as part of the follow-up activities of CONFINTEA VI for the Asia-Pacific region. This review of community learning centres in Bangladesh, Indonesia, Mongolia, the Republic of Korea, Thailand and Vietnam reports that such centres have become increasingly important in these countries. Although different models, legislation and policies exist from country to country, they provide illustrations of local, often citizen-led and NGOconvened, learning opportunities linked to broader conceptions of improving the quality of life and contributing to local development. Whilst they do not label themselves as 'learning cities', there is a strong connection between the principles inherent to community learning centre models in these Asian countries, and the learning city concept, not least in the principle of providing learning opportunities to all citizens within a defined geography. Similar analogies have been made in Europe in relation to community learning initiatives (Sankey and Osborne 2006), and in Asia by (Yang et al. 2015) not all initiatives that are learning cities/regions truly fulfil the generally understood requirements to use that label, whilst many that do not use the nomenclature do manifest such characteristics.

The features of strong legislation and regulation combined with a collective and community-based ethos seem to be born out in analysis of international initiatives that the PASCAL Observatory has undertaken within the PASCAL International Exchanges (PIE) and Learning Cities Network (LCN), which now we discuss in some detail.

PIE was launched in 2009 with 21 member cities, including six from Asia (Beijing, GwangMyeong, Hong Kong, Iida, Seoul and Shanghai) with the following objectives:

- to facilitate and support international exchanges of ideas and experience between participating communities and institutions directed at the role of cultural institutions, libraries and heritage learning in encouraging and supporting learning throughout life for all.

- to use the exchanges to reconceptualise the role of cultural institutions, libraries and heritage learning in community and regional development through a lifelong learning lens.

- to encourage ongoing international exchanges of new ideas and experience between participants.

- to utilize the resources and expertise of PASCAL to support and facilitate the international exchange of ideas, experience and people between learning communities and regions.

PIE resulted in community-community linkages between municipal authorities and associated agencies in four continents. This has included drawing on those designated as learning 'towns' or 'communities', in Australia, with those involved with community-based research in Canada and Learning Cities work in Europe and Asia, and has included both virtual and face-to-face interactions. It also led to more formal, larger institution initiatives to link city-wide art galleries, libraries and museums on different continents in shared initiatives which have explored innovative ideas about how they contribute to lifelong learning. In this type of collaboration, PIE has developed specific opportunities in conjunction with key regional conferences around the work. It also generated Stimulus Papers from cities themselves as well as it own conceptual papers. Those from the Asia cities illustrate very specific orientations within learning city development reflective of national concerns in relation to lifelong learning, and add weight to a number of the observations that we have already made. Most notable is the emphasis of community that Han and Makino (2013, p. 435) have reported, and which has also been highlighted by Kearns (2015).

For example, in both Beijing and Shanghai, the Learning City initiatives aim through a process of community network to reach down to individual streets with $80 \%$ of streets in Beijing having established community education centres or learning centres (Yuan 2012, p. 3). Similarly in Shanghai, community educational institutions have been located all across each of the city's 18 districts and counties 
(Huang 2013, p. 2; SMILE 2013, p. 122). These comprehensive developments have come about because of a strong centralized top-down organizational structure. For example, in Beijing, there is a Municipal Leadership Group for Constructing the Learning City Project that has been given the task:

"of implementing the policies and measures in promoting the learning city construction issued by the municipal government and committee of the Chinese Communist Party, organizing and constituting working objectives, implementing plans and policy documents, studying and solving important issues in learning city construction, and assessing progress". (Yuan 2012, p. 4)

We can also observe in Chinese initiatives the desire to imbue citizens through the development of a learning society, a life-deep approach. Huang (2013 p. 4-5) in her report of Shanghai's learning city suggests that the 'most important inner motivation for building a learning society' $\ldots$ is ... 'that the general public establishes the idea of envisions lifelong learning as a way of living'. As Kearns (2015 p. 159) has observed, the Chinese cities under particular Chinese conditions of governance demonstrate policy and development at three levels (neighbourhood, district, and city) with this tripartite model showing close correspondence to the ideas of the American urbanist Jane Jacobs (1992, p. 117-132) on city development. Kearns further asserts that these models (also found in Taiwan), and which he describes as a second generation of learning cities in East Asia, are significantly different from the first generation that emanated in the west. They demonstrate forms of partnership and governance linked to a strong research base, capitalising on cultural heritage, social objectives and the desire for economic transformation.

In the case of Korea, we have already referred to the particular focus on learning cities within the Lifelong Learning Law of 2008, and we can see as in China of an highly organised and centrally driven system in the papers of Choi (2013) related to GwangMyeong and Lee (2013) in relation to Seoul. However, there is however a strong sense to devolution of responsibility to the cities and the integration of lifelong learning into urban development, attributed by Han and Makino (2013) to the restoration of self-governance in the early 1999s in Korea. The legal designation of NILE as a driver for learning city development has been very important. The focus in Korean learning cities, as in China and Japan, includes art and cultural offerings, which Han and Makino suggest is a reflection of some of the best aspects of Confucianism. In a sense, however, this is similar to historical traditions in other parts of the world, notably within the UK and the Nordic countries, which were strongly based on socio- democratic, cooperative and socialist ideas; although as we have suggested earlier, now these offerings are largely consigned to a past age. However, none of these European countries has approached the comprehensive nature of the offer in Korean cities.

The role of the city in taking leadership and responding to the demands of communities is also a feature of Japanese models, as illustrated by Makino's (2014) paper about Iida. $\mathrm{He}$ argues that this stems from an amendment of the Fundamental Law of Education in 2006, and that:

"policymakers advocated "the development of selfreliant individuals and reconstruction of 'social ties' through learning activities," which, in turn, would contribute to "the solution of local issues" (Lifelong Learning Working Group, Central Education Council, 2011 cited in Makino 2014, p. 8)

The most significant aspect of Maclean's (2013) Stimulus Paper from Hong Kong was the issue of internal migration from China. Many of these migrants are poorly educated middle-aged women who take up low-waged menial jobs, having married displaced local workers from the previous industrial era. The children of these families inevitable fall into a poverty trap, and the challenge therefore is to create opportunities that cross generations in families. Whilst there is no overall governmental initiative that is tacking these issues of immigration, the report highlights work within the Sham Shui Po District Council that seeks to tackle poverty alleviation through training both of children (as community reporters) and their parents (as artists and tour guides).

These issues were taken up in PASCAL's Hong Kong conference in November 2013, which was its first in Asia and was seen as a watershed in the further development of PASCAL international interests in the challenging context posed by rapid urbanisation and globalisation, and the patterns of learning city development in East and West. Thereafter, PASCAL developed a major new programme, Learning Cities and Regions for the 21st century, directed towards regional governments, and created the Learning Cities Network. Within Asia the LCN has included Duhok, Erbil, Nam-gu Incheon, Suncheon and Taipei, and a range of sub-networks each with a specific theme. What is notable amongst the Asian cities involved has been the specific focus of interest. In war-torn Iraqi Kurdistan, the cities of Duhok and Erbil both have used their cultural assets as the fulcrum for the development of learning cities, in the case of Erbil, utilizing the UNESCO Heritage listed Erbil Citadel as an open air museum and learning environment. It is perhaps Taipei that has most significantly impacted on PASCAL's development and which has led to knowledge transfer from east to west. We now focus on this city in more depth. 


\section{The case of Taipei and EcCoWell}

Taipei's Cultural City is one of six strands in its Learning City development, and its case is of particular interest given the holistic nature of its efforts. The unifying vision of Taipei Learning City involves six strands: Cultural City, Eco City, Waterfront City, Healthy City, Safe City, Welfare and Wellbeing City as was presented though a number of papers at a recent Learning cities conference in there. It is a vision that exemplifies, and stimulated, the creation of a model that has permeated PASCAL thinking, EcCoWell, an approach that argues that learning, health, community building, and cultural policies collectively contribute to the well-being of citizens and their families (Kearns 2012).

In Taiwan, the implementation of lifelong learning initiatives combines both top-down and bottom-up approaches. The Taiwanese government's White Paper, Towards a Learning Society (Government of Taiwan 1998), was introduced as a response to the global trends to develop lifelong learning policy and at the same time aimed to respond to the public need for continuing learning. Subsequently, in 2002 the Lifelong Education Act was promulgated in order to promote education as a tool for developing Taiwanese society. In 2010, the Ministry of Education proposed 'The Action Year for Lifelong Learning $331^{\prime}$, encouraging the public to spend at least $30 \mathrm{~min}$ learning, $30 \mathrm{~min}$ doing exercise and to undertake one activity for the common good per day (Ministry of Education, Taiwan 2010). Despite political tensions, ${ }^{2}$ the Taiwanese government has made an attempt to emphasize the importance of lifelong learning (for both individuals and society at large) and encouraged citizens to play an active role in building a learning society (Chang et al. 2012). Similarly, the adaptation of learning city policies in Taiwan created a strategic framework for implementing lifelong education in regional communities.

In Taipei, the Learning City project was established to promote an inclusive, prosperous and sustainable urban community. In 2012 the Declaration of Taipei as a Learning City was issued, and in adopting the rhetoric of lifelong education, Taipei aimed to generate socio-economic benefits. This is in line with Power and Maclean's (2011) theoretical understanding where lifelong learning is seen as (1) a basic human right for individual development and empowerment; (2) a means to improve employment opportunities and higher income; (3) a strategy for poverty alleviation; (4) an approach to generate higher productivity and social capital; (5) a tool to achieve the national vision.

\footnotetext{
${ }^{2}$ From 2000 onwards the Democratic Progressive Party (DPP) gained power over the Nationalist Party (NP), but the latter still holds the majority of seats in the Parliament influencing educational legislation.
}

In Taipei, at the level of practice one can observe that Power and Maclean's (2011) principles of lifelong learning are achieved through the promotion of community-based learning, a common trait in other Asian cases. Notable, however is the distinct role of the 12 Community Colleges (one per each city district) to provide learning opportunities for residents across the city. Types of courses for adult learning offered by the Colleges support the tripartite model (Kearns 2015) where the values of the city, district and neighbourhood are brought together in order to create meaningful and beneficial learning experiences. Apart from the focus on developing vocational skills and workplace competences, colleges offer programmes, which highlight the importance of cultural heritage, dedicated to traditional Chinese art, dance and music. Moreover, colleges promote the concept of community (re)building to create another dimension of learning. The local challenges, identified within the city, district and neighbourhood areas, are used to activate a sense of collective (as opposed to the individualistic European culture) identity. Some of the programmes include building green organic gardens to reduce pollution, organizing secure school routes for students, developing food banks or creating a community friendly to visually impaired. The logic is that designing learning projects, which are relevant to experiences of the local community, encourages citizens to play an active role in social development.

As in many other Asian and European countries, Taiwan faces a number of challenges related to lifelong learning which relate to issues of migration, multiculturalism, changes in the labour market and an ageing population. As Wang (2008) indicates, in Taiwan, the nature of social change has to become a starting point for improvement of lifelong learning policy and practice. For him, setting the objectives for lifelong learning has to be in line with the contextual realities of the given place. The case of Taipei, and Taiwan in general, provides an example of a comprehensive and contextualized place-based approach. Many places around the world proclaim themselves to be learning towns, cities or regions, and it is possible to find examples of all of the initiatives found in Taipei in particular cases. Often, however, these are discrete and not part of an overarching strategy. What differentiates Taipei is the extent of development of a comprehensive city-wide system linked to a strong legislative structure and a city-led plan for implementation.

\section{Analysis of journals' themes}

In order to generate a further perspective on Asian lifelong learning based on academic literature that emanates from the west, a content analysis of three journals was conducted 
to establish the most prevalent thematic areas of interest amongst Asian perspectives. These journals, namely, The International Journal of Lifelong Education, Adult Education Quarterly and the International Review of Education, were sampled to represent the nature of the international debate on lifelong education and learning. These were chosen on the basis of being leading journals in the field on the basis of their QScore, a metric utilized in Australia with wider applicability that ISI Impact Scores. QScore gives highest weighting to the views of educators and has greater coverage than ISI Impact Score. Of 49 journals in the field of vocational further and adult education, only 3 had an ISI Impact Score according to a study by Fairburn et al. (Fairbairn et al. 2009). QScores for IJLE (15.39), AEQ (15.02) and IRE (13.89) make them the three of the four highest rates journals in the field (the other is the Australian Journal of Adult Education, which was omitted on the basis that rankings are biased to Australia).

The first step involved generating a database of all articles written from an Asian perspective published in each journal within the last 10 years (between 2006 and 2016). Having this panoramic view exposed that the proportion of articles that originates from this perspective is low in relation to population of researchers by comparison with Europe and North America. The Asian share stands at just over $8 \%$ in both the International Journal of Lifelong Education, and the International Review of Education and almost $4.5 \%$ in Adult Education Quarterly, respectively. This parochialism is common place in Education journals with (Fairbairn et al. 2009) reporting that across 1042 journals in the field, author affiliation is very concentrated with $95 \%$ represented by 10 countries. And it is clear that in the sampled journals, theories and models of analysis originate mostly from a Western perspective from western authors. Of course there are potential explanations of this phenomenon, including that of the dominance of the English language, and representing the breadth of issues within adult education and lifelong learning is challenging, but Western-centrism of perspectives can distort our holistic understanding of issues linked with lifelong learning internationally. Makino (2014) has argued that many of the frameworks for lifelong learning are based on Western assumptions, which may not be applicable to Asian culture. For example, as we suggested previously in pre-dominance of individualisation in the west, where focus is based upon individual competency, has less attraction in Asian cultures, which have been based on the principles of collective identity. One feature of responsibility in research is to work towards an understanding of education that is multiple and rich, rather than parochial.

For the three journals, despite the relatively small proportions of articles published from an Asian perspective, we still were able to assess 76 papers. Our next step involved grouping articles into themes, in order to identify the most prevalent areas of interest. The most significant themes, policy narratives, community-based learning and well-being of older people, ${ }^{3}$ appear to support the Asian sense of collectivism. That is not to say that 'the individual' becomes devaluated, but the sense of self is constructed through the prism of social values.

\section{Policy narratives}

Within policy narratives, which accounted for some $29 \%$ of papers, the unifying theme for Europe and Asia of Learning Cities is prevalent. Confirming our previous analysis based on a wider literature, these papers largely express the Asian rhetoric of social collectivism as against the pre-dominant theme from Europe of employability. Indeed, overall in our sample, relatively few papers written from an Asian perspective contained themes related to employment (just over $5 \%)$. The four identified papers relate to the income inequality in Singapore (Millie and Morris 2016), factors affecting career planning in China and Denmark (Zhang 2016), skills development in the informal sector in India (Pilz et al. 2015) and career transition in the post-retirement employment in Korea (Kim 2013).

\section{Community-based learning}

As we reported earlier in Asia through lifelong learning activities, people are encouraged and indeed in some cases expected to be involved with social and political activities for the betterment of society. Consequently, the dominant type of adult learning focuses upon hobbies, liberal arts and community (re)building. These humanistic and ethical principles underpin the context of Asian lifelong learning and are represented in just over $14 \%$ of the papers. Amongst the papers within this category is that of Ogawa (2009) who argues that Japanese policy through lifelong learning ought to build stronger links with the global market trends. Similarly, Han (2011) who reports that in the Republic of Korea, the state and local authorities through lifelong learning aim to support people with little chances of entering the labour market (e.g. elderly people). As a consequence, particular courses are provided. However, Han argues that the emergence of new jobs related to the knowledge economy can trigger a shift in the lifelong education in Asian countries. Community-based learning overlaps with the next most prevalent area of interest, namely the concept of well-being of elderly people.

\footnotetext{
${ }_{3}$ Some of the articles were classified within more than one thematic area.
} 


\section{Well-being of elderly people}

Over $10 \%$ of papers focused on this topic, and it is perhaps not surprising given that Japan, Republic of Korea and Taiwan are each currently experiencing an ageing of their populations (Dhirathiti 2014). Later life learning is seen as a solution to many of the governments' concerns related to the costs of welfare, care, and health provision for elder people. Kee (2010), for example, indicates that in the Republic of Korea, community-based learning centres for elderly people organise social groups meetings, hobby clubs with cultural activities and volunteering projects to provide personal growth and self-fulfilment for senior citizens. Similarly, promoting mental well-being and resilience is becoming a crucial element of learning for older people. In 2014, Korea had the second (after Lithuania) highest suicide rate among OECD countries. Senior citizens' suicide rates are much higher than among young or middle-aged people. The suicide rate for those aged over60 was 54.6 (per 100,000 persons) and increases to 80.2 for over-70 population (Kee 2010). Poverty along with medical illness and family conflicts has been blamed for the growing numbers of suicide among senior citizens. Consequently, Kee's argument is that it is necessary for senior citizen education to address issues of emotional well-being and to re-establish their connections in the family and society.

\section{Concluding comments}

Based on this analysis of foci for adult education in Asia by comparison to the west, and in particular one field of learning cities, we can identify both similarities and differences in emphasis between Europe and Asia.

The desire to promote well-being of citizens, whether economically or more broadly in terms of their health and well-being, and access to all of assets of society is universal. Common challenges exist in both Europe in Asia and indeed in all parts of the world with the importance of adult education in addressing these encapsulated in the revised UNESCO Recommendation on Adult Education, which was adopted at the UNESCO General Conference in November 2015:

Adult learning and education constitutes a major building block of a learning society, and for the creation of learning communities, cities and regions, as they foster a culture of learning throughout life and revitalize learning in families, communities and other learning spaces, and in the workplace. (UNESCO 2015b)
Such sentiments were also promulgated within Incheon Declaration, Education 2030, at the World Education Forum (2015). The challenges are global and are illustrated for example in the UN's sustainable development goals (SDGs), in development aid programmes such as those of agencies such as EuropeAid and AusAid in Asia, and at a national level, the work of DVV (Deutscher Volkhochschule-Verband) from Germany and UK's Global Challenges Research Fund (GCRF) in the continent. SDG 4 seeks to 'ensure inclusive and equitable quality education and promote lifelong learning opportunities for all' (UN 2015). DVV's work in Asia, working with local agencies is broad-based and constructed in afford with local concerns related to democratization, community building, work environments and health. As with the UK GCRF initiative, there is a concern with strengthening the capacity of institutions, in this case with a focuses on five inter-connected areas: secure and resilient food systems supported by sustainable agriculture; sustainable health and well-being; inclusive and equitable quality education; clean air, water and sanitation and renewable energy and materials. It is illustrative of the perception that there is a core role for education, including adult education, within the context of the truly global problems, and we can see examples of these challenges being promulgated at the forefront of Asian adult learning policies.

However, when analysing Asian models of adult and lifelong learning through the lenses of societal learning, the development of a learning society and learning communities, distinctions with European perspectives are not completely clear-cut. It is certainly the case that a human capital perspective pervades policy narratives in states in both Asia and Europe, but also that the broader conceptions of lifelong learning as conceived in the original conceptions of learning society are more strongly expressed in Asia. This breadth of concern with learning seems to find significant expression not only within learning city development especially in China, Korea and Taiwan, but also in specific initiatives in these and other countries in the continent, particularly those concerned with inclusion of older people, health and well-being, and community building. Lifelong learning often in Asia is conceived as the underpinning for securing a harmonious rather than a learning society, and whilst both objectives to an extent are nebulous and difficult to achieve, many Asian countries have legislation and structures, combined with strong city-level policies that are put into practices on the ground. At the same time at community-level, a collectivist philosophy permeates day to day living in many societies, and adult learning to an extent takes on a life-deep orientation based on embedded or ideological belief system as opposed to either an humanist purpose focusing on self-actualisation or a functional purpose of economic development. 
We focused specifically in our analysis on learning city development as an illustration of a particular facet of Asian development. The challenges that face cities in an era of rapid urbanization requires a cross-sectoral, inter-disciplinary that links sustainable development to education, health and well-being at the appropriate geographical scale. This is well conceptualized in PASCAL's ECCoWell model (Kearns 2012), which was stimulated from Taipei's initiative and translated for use elsewhere in the world. The mixture of a top-down interventionist approach together with bottom-up community development there and in a number of Asian learning cities illustrates possibilities for adult educators to work on a wider canvas. From the perspective of societal learning, models from Korea and Taiwan illustrate the development of networks though the mobilization of actors working collaboratively to develop city-wide opportunities than span the formal and non-formal sector. Further, we can observe in these initiatives the development of learning cities, community by community, as anticipated in the learning community model proposed by Faris $(2005,2010)$. Ultimately our analysis suggests that whilst there is a certain distinctiveness in Asian approaches to adult and lifelong learning, much of this work is not captured in the academic literature within the field that emanates from the West.

Open Access This article is distributed under the terms of the Creative Commons Attribution 4.0 International License (http://crea tivecommons.org/licenses/by/4.0/), which permits unrestricted use, distribution, and reproduction in any medium, provided you give appropriate credit to the original author(s) and the source, provide a link to the Creative Commons license, and indicate if changes were made.

\section{References}

Allemendinger, J., \& Nikolai, R. (2010). Bildungs- und Sozialpolitik: Die zwei Seiten des Sozialstaates im internationalen Vergleich. Soziale Welt, 61, 105-119.

Allmendinger, J., \& Leibfried, S. (2003). Education and the welfare state: The four worlds of competence production. Journal of European Social Policy, 13(1), 63-81.

Boriboon, G. (2016). Guidelines for basic education approach for migrant laborers in the Bangkok metropolitan area. Paper presented at ASEM LLL Hub Symposium, Supporting Adult Education for a Sustainable Life Course: Asian and European perspectives on Education, Work and Citizenship. Glasgow 6-8 June 2016.

Byun, J. I., Kwon, I. T., Kim, N. S., Yang, B. C., \& Yang, H. G. (2005). Practices of lifelong learning cities for the development of regional community. Seoul: KEDI.

Chang, D.-F., Wu, M.-L., \& Lin, S.-P. (2012). Adults engaged in lifelong learning in Taiwan: Analysis by gender and socioeconomic status. Australian Journal of Adult Learning, 52(2), 310-355.

Choi, D. M. (2013). GwangMyeong stimulus paper. http://pobs.cc/ $15 \mathrm{pmh}$.
Commission of the European Union. (2000). Communique of the Lisbon summit of the education committee of the council of the EU strategy for lifelong learning. Luxembourg: EC Publications.

Commission of the European Union. (2001). The local and regional dimension of lifelong learning: A policy paper. Brussels: European Commission.

Commission of the European Union. (2003). Information note: The " $R 3 L$ initiative" European networks to promote the local and regional dimensions of lifelong learning. Brussels: European Commission.

Delors, J. et al. (1996). Learning: The treasure within. The report to UNESCO of the International Commission on Education for the Twenty-first Century. Paris, UNESCO.

Dhirathiti, N. (2014). Lifelong learning policy for the elderly people: A comparative experience between Japan and Thailand. International Journal of Lifelong Education, 33(6), 770-790.

Eckert, T., Preisinger-Kleine, R., Fartusnic, C., Houston, M., Juceviciene, P., Dillon, B., et al. (2012). Quality in developing learning cities and regions: $A$ guide for practitioners and stakeholders. Munich: Ludwig Maximilian University.

European Commission. (2010). EUROPE 2020 - A strategy for smart, sustainable and inclusive growth. Brussels: EC.

European Commission. (2013). Follow-up on the implementation by the Member States of the 2008 European Commission recommendation on active inclusion of people excluded from the labour market - Towards a social investment approach. Brussels: EC Staff Working Document.

Eurostat. (2015). Underemployment and potential additional labour force statistics. http://ec.europa.eu/eurostat/statistics-explained/ pdfscache/12449.pdf.

Fairbairn, H., Holbrook, A., Bourke, S., Preston, G., Cantwell, R., \& Scevak, J. (2009). A profile of education journals. In P. Jeffrey (Ed.) Proceedings of Australian Association for Research in Education, 2008.

Faris, R. (2005). Lifelong learning, social capital and place management: A Canadian perspective. In C. Duke, M. Osborne, \& B. Wilson (Eds.), Rebalancing the social and economic: Learning, partnership and place. Leicester: NIACE.

Faris, R. (2010). Learning community by community - Preparing for a knowledge-based society. Education Canada, 43(1), 4-43.

Faure, E., et al. (1972). Learning to be: The world of education today and tomorrow - The report to UNESCO of the International Commission on the Development of Education. Paris: UNESCO.

Fejes, A. (2010). Discourses on employability: Constituting the responsible citizen. Studies in Continuing Education, 32(2), 89-102.

Government of India Planning Commission. (2006). Report of the steering committee for secondary, higher and technical education. Delhi: Government of India Planning Commission.

Government of Japan (2008) Basic plan for the promotion of education. http://www.mext.go.jp/en/policy/education/lawand plan/title01/detail01/1373797.htm.

Government of Taiwan. (1998). Toward a learning society. Taipei: Ministry of Education. http://english.moe.gov.tw/ct.asp?xItem= $7042 \& \mathrm{ctNode}=784 \& \mathrm{mp}=11$.

Han, S. (2011). Asia needs humanistic learning. ASEMagazine for Lifelong Learning, pp. 9-10.

Han, S., \& Makino, A. (2013). Learning cities in East Asia: Japan, the Republic of Korea and China. International Review of Education, 59(4), 443-468.

Hanushek, E. A., Woessmann, L., \& Zhang, L. (2011). General education, vocational education and labour market outcomes over the life-cycle. Bonn: Forschunginstitut zur Zukunft der Arbeit. Discussion Paper 6038.

Heisig, J. P., \& Solga, H. (2014). Skills inequalities in 21 countries PIAAC results for prime-age adults. Berlin: 
Wissenschaftszentrum Berlin für Sozialforschung. Discussion Paper SPI 2014-503.

Heywood, J. \& Jirjahn, U. (2015). The German labor market for older workers in comparative perspective. Research Papers in Economics, 2: 15. Trier: University of Trier.

Houston, M., Krüger, K., Molas, A., Osborne, M., \& Jiménez, L. (2016). Cooperation in work-oriented learning in higher education. PEOPLE, 2(1), 685-705.

Huang, J. (2013). Shanghai stimulus paper. http://pobs.cc/16p9v.

Husén, T. (1974). The learning society. London: Methuen.

Husén, T. (1986). The learning society revisited. Oxford: Pergamon.

Jacobs, J. (1992). The death and life of great American cities. New York: Vintage Books.

Jarvis, P. (2007). Globalization, lifelong learning and the learning society: Lifelong learning and the learning society (Vol. 2). London: Routledge.

Kearns, P. (2012). Living and learning in sustainable opportunity cities. http://pie.pascalobservatory.org/eccowell.

Kearns, P. (2015). Learning cities on the move. Australian Journal of Adult Learning, 55(1), 153-168.

Kee, Y. (2010). Educational gerontology in Korea: An interpretive and critical study. International Journal of Lifelong Education, 29(1), 93-110.

Kim, S. (2013). The career transition process: A qualitative exploration of Korean middle-aged workers in postretirement employment. Adult Education Quarterly, 64(1), 3-19.

Larsen, K. (1999). Learning cities: the new recipe in regional development. OECD Observer, August 1999. Paris: OECD.

Lee, J. (2013). Seoul stimulus paper. http://pobs.cc/15p45.

Longworth, N. (2003). Lifelong learning in action: Transforming education in the 21st century. London: Kogan Page.

Maclachlan, K., \& Osborne, M. (2009). Lifelong learning, development, knowledge and identity. Compare: A Journal of Comparative and International Education, 39(5), 575-583.

Maclean, R. (2013) Hong Kong stimulus paper. http://pobs.cc/16pnf.

Makino, A. (2014). Is the idea of learning city too European? ASEMagazine for Lifelong Learning, pp. 20-25.

Millie, L., \& Morris, P. (2016). Lifelong learning, income inequality and social mobility in Singapore. International Journal of Lifelong Education, 35(3), 286-312.

Ministry of Education, Science and Technology. (2009). Lifelong learning act. http://www.moleg.go.kr/english/korLawEng?pst Seq $=52187$.

Ministry of Education. Taiwan 2010. Education in Taiwan: 20102011. https://stats.moe.gov.tw/files/ebook/Education_in_Tai wan/2010-2011_Education_in_Taiwan.pdf.

Ministry of Higher Education. (2011). Blueprint on lifelong learning for Malaysia 2011-2020. Putrajaya: Ministry of Higher Education.

Mwaikokesya, M. J. D., Osborne, M., \& Houston, M. (2014). Mapping lifelong learning attributes in the context of higher education institutions. Journal of Adult and Continuing Education, 20(2), 21-36.

National Institute for Lifelong Education. (2013). Lifelong learning in Korea (2013) - The 3rd. national lifelong learning promotion plan (2013-2017). Seoul: NILE.

National Institute for Lifelong Education \& UNESCO Institute for Lifelong Learning (NILE/UIL). (2017). Synthesis report on the state of community learning centres in six Asian countries. Seoul/Hamburg: NILE/UIL.

OECD. (1992). Study prepared for the congress on educating cities. Paris.

OECD. (2000). Cities and regions in the new learning economy. Paris.
OECD. (2013). All in it together? The experience of different labour market groups following the crisis. OECD employment outlook 2013. Paris: OECD.

Ogawa, A. (2009). Japan's new lifelong learning policy: exploring lessons from the European knowledge economy. International Journal of Lifelong Education, 28(5), 601-614.

Osborne, M. (2003). University continuing education in the United Kingdom. In M. Osborne \& E. Thomas (Eds.), Lifelong learning in a changing continent: Continuing education in the universities of Europe (pp. 463-485). Leicester: National Institute of Adult Continuing Education.

Osborne, M. (2014). Why lifelong learning and why learning cities? Pedagogy, 86(7), 1067-1077.

Osborne, M., Kearns, P., \& Yang, J. (2013). Learning cities: Developing inclusive, prosperous and sustainable urban communities. International Review of Education, 59(4), 409-423.

Pilz, M., Uma, G., \& Venkatram, R. (2015). Skills development in the informal sector in India: The case of street food vendors. International Review of Education, 61(2), 191-209.

Power, C. \& Maclean, R. (2011) Lifelong Learning for Poverty Alleviation and Sustainable Development. Background Concept Paper for the International Symposium of Lifelong Learning for Poverty Alleviation and Sustainable Development: Developing a Research Agenda for Asia-Pacific. Hong Kong Institute of Education, 12-13 January 2011. https://www.ied.edu.hk/isll/ Download\%20Files/Panel2_Prof_Colin_Power.pdf.

Raggett, P., Edwards, R., \& Small, N. (1995). The learning society: Challenges and trends. London: Routledge.

Ranson, S. (Ed.). (1998). Inside the learning society. London: Cassell.

Sandberg, F., Fejes, A., Dahlstedt, M., \& Olson, M. (2016). Adult education as a heterotopia of deviation: A dwelling for the abnormal citizen. Adult Education Quarterly, 66(2), 103-119.

Sankey, K., \& Osborne, M. (2006). Lifelong learning reaching regions where other learning doesn't reach. In R. Edwards, J. Gallacher, \& S. Whittaker (Eds.), Learning outside the academy: International research perspectives on lifelong learning (pp. 202-223). London: Routledge.

Shanghai Municipal Institute for Lifelong Education (SMILE). (2013). Shanghai development: Report of lifelong education. Shanghai: SMILE.

Sun, Q. (2007). A critical view on building learning cities in China: Lifelong learning as a vehicle towards a harmonious society. Convergence, 40, 95-116.

Sungsri, S. (2009). Lifelong learning in Thailand: Policy and implementation. http://asemlllhub.org/fileadmin/www.dpu.dk/ asemeducationandresearchhubforlifelonglearning/conferences/ rigapresentations/resources_2593.pdf.

UN. (2015). Transforming our world: The 2030 agenda for sustainable development. Resolution adopted by the General Assembly on 25 September 2015. http://www.un.org/ga/search/view_doc. asp?symbol=A/RES/70/1\&Lang=E.

UNESCO. (2015a). Asia-Pacific regional education for All report - A synthesis of the National EFA Reports. Paris: UNESCO.

UNESCO. (2015b). Recommendation on adult learning and education. http://unesdoc.unesco.org/images/0024/002451/245179e.pdf.

UNESCO Institute for Lifelong Learning. (2014). International Conference on learning cities - lifelong learning for all: Inclusion, prosperity and sustainability in cities. Beijing, 21-23 October 2013, Conference Report. Hamburg: UNESCO Institute for Lifelong Learning.

Wallin, E., Henningsson, S., \& Möller, M. (2005). The higher value chain of eLearning. Heidelberg: Physica-Verlag HD.

Wang, C.-Y. (2008). Enhancing the interactive relationship between lifelong learning and social changes to carry out a learning 
society in Taiwan. International Journal of Lifelong Education, 27(5), 535-542.

World Education Forum. (2015). Incheon declaration, education 2013: Towards inclusive and equitable quality education and lifelong learning for all. http://www.uis.unesco.org/Education/ Documents/incheon-framework-for-action-en.pdf.

Yang, J. (2012). An overview of building learning cities as a strategy for promoting lifelong learning. Journal of Adult and Continuing Education, 18(2), 97-113.

Yang, J., Yorozu, R., \& Lee, K. (2015). Building a learning society in Japan, the Republic of Korea and Singapore. Hamburg: UNESCO Institute for Lifelong Learning.
Yorks, L., \& Barto, J. (2015). Workplace, organizational, and societal: Three domains of learning for 21st-century cities. New Directions for Adult and Continuing Education, 145, 35-44.

Yuan, D. (2012). Beijing stimulus paper. http://pobs.cc/16plw.

Zhang, Z. (2016). Lifelong guidance: How guidance and counselling support lifelong learning in the contrasting contexts of China and Denmark. International Review of Education, 62(5), 627-645. 